\title{
A Study of Evaluation for the Management of Diabetes in Bangladesh
}

\author{
Zakia Sultana $^{1 *}$, Md. Ershad Ali ${ }^{2}$, Most. Afia Akhtar ${ }^{1}$, Md. Sala Uddin ${ }^{3}$, Md. Mominul Haque ${ }^{4}$ \\ ${ }^{1}$ Department of Pharmacy, Rajshahi University, Rajshahi, Bangladesh; ${ }^{2}$ Department of Chemistry, Dhaka College, National Univer- \\ sity, Dhaka, Bangladesh; ${ }^{3}$ Department of Chemistry, Rajshahi University, Rajshahi, Bangladesh; ${ }^{4}$ Department of Chemistry and Bio- \\ molecular Sciences, Macquarie University, Sydney, Australia. \\ Email: *zakia.sultanaru@gmail.com
}

Received March $16^{\text {th }}, 2013$; revised May $6^{\text {th }}, 2013$; accepted May 20 ${ }^{\text {th }}, 2013$

Copyright (c) 2013 Zakia Sultana et al. This is an open access article distributed under the Creative Commons Attribution License, which permits unrestricted use, distribution, and reproduction in any medium, provided the original work is properly cited.

\begin{abstract}
Diabetes Mellitus is a leading cause of death in present world. This study was carried out to evaluate the management, control, complication profile and treatment strategies in patients with diabetes and to determine what extent management of diabetes in a tertiary-care diabetic hospital in Bangladesh adhered to current guidelines. Total 140 diabetic patients (type-1 = 3, type-2 = 137) were randomly selected from outpatient department of a tertiary care diabetic hospital in the Rajshahi city, Bangladesh, during the month of August to September. A standard questionnaire was constructed in local language and interview was administrated. The result was expressed as mean \pm SD and the age was $53.2 \pm 10.5$ yr, duration of diabetes was $6.3 \pm 5.6 \mathrm{yr}$ and age at the onset of diabetes was $46.9 \pm 9.9 \mathrm{yr}$. The study group comprised of about $43 \%$ male and 57\% female with varying risk factors including family history (49\%), smoking (11\%) and both smoking and family history (4\%). Results showed deteriorating glycemic control with mean FBG (fasting blood glucose) and PPG (postprandial blood glucose) level was $8.9 \pm 3.6 \mathrm{mmol} / \mathrm{L}$ and $11.2 \pm 4.7 \mathrm{mmol} / \mathrm{L}$ respectively. About 25\% patients had FBG level < $6.1 \mathrm{mmol} / \mathrm{L}, 24 \%$ had FBG $6.1-7.8 \mathrm{mmol} / \mathrm{L}$ and rest 51\% had FBG $>7.8 \mathrm{mmol} / \mathrm{L}$. Of the 51\% patients with hypertension, $94 \%$ were taking anti-hypertensive medicine and $21 \%$ patients with dyslipidemia, $59 \%$ were treated with lipid lowering agents. Micro-vascular and Macro-vascular complications were reported in 49\% and 11\% patients respectively. The rates of diabetic complications were cataract $19 \%$, diabetic retinopathy $14 \%$, neuropathy symptoms 35\%, nephropathy 6\%, MI 6\%, cerebral stroke 4\% and history of angina pectoris was 7\%. Proportion of patients on diet control alone, oral hypoglycemic agent (OHA), insulin and combination of insulin \& OHA was 10, 44, 25 and 21 percent respectively. Quality of life evaluation showed that about half of patients have poor quality of life as well as poor adherence to diet, exercise and self testing of blood glucose. In conclusion, majority of the patients were still not satisfactorily controlled. There is an urgent need for effective remedial measures to increase adherence to practice guidelines and to educate both patients and healthcare personnel on importance of achieving clinical targets for metabolic control.
\end{abstract}

Keywords: Diabetes; Management; Blood Glucose; Clinical Targets; Metabolic Control

\section{Introduction}

Diabetes mellitus is one of the most common chronic diseases affecting millions of people worldwide with a large negative impact on the patient's health [1]. It is a major threat to global public health that is rapidly getting worse and the biggest impact is on adults of working age in developing countries. Diabetes is the third leading fatal disorder after cancer and heart disease [2].

In world Diabetes Day 2011, the new figure has been

${ }^{*}$ Corresponding author. estimated that the number people living with diabetes are expected to rise from 366 million in 2011 to 552 million by 2030, if no urgent action is taken. The disease is now a worldwide epidemic. The diabetic population in Asia has increased dramatically. The developed countries such as India, China, and the USA are presently the countries with the leading number of diabetes. Furthermore, three new people at every ten seconds or almost ten million people per year are affected by diabetes [3]. In most developing countries at least one in ten deaths in adults aged 35 to 64 is attributable to diabetes and in some the 
figure is as high as one in five. In 2010, there were 285 million people with diabetes worldwide and by 2030 this figure is expected to nearly double to reach a total of 439 million [4].

Clinically diabetes mellitus is associated with a number of micro vascular (e.g. retinopathy, nephropathy, and neuropathy) as well as macro-vascular (e.g. myocardial infarction, peripheral vascular disease, and stroke) complications that result in significant morbidity and mortality $[5,6]$. Recent evidence suggests that diabetes is associated with a high risk of cardiovascular disease (CVD) [7-9]. Individuals with diabetes have an absolute risk of major coronary events similar to that of non-diabetic individuals with established coronary heart disease (CHD) [10-12]. Furthermore, after an acute coronary event diabetic subjects develop congestive heart failure more frequently and have a higher mortality rate than non-diabetic individuals [13]. A greater burden of risk factors is at least partly responsible for the increased risk of CHD in diabetes [11]. Heart disease is a major complication and the leading cause of premature death among people with diabetes mellitus. At least 65 percent of people with diabetes die from heart disease or stroke [14]. Because diabetes mellitus leads to multiple complications, such as blindness, kidney failure, amputations, strokes and heart attacks, it is considered to be a devastating illness [15]. The incidence of diabetes in the Asian population is on the rise; hence the incidence of late diabetes complications is also expected to increase correspondingly. Amongst the countries in Asia India has got the highest number of people suffering from diabetes. When it comes to impaired glucose tolerance, Indonesia and Singapore figure in the top ten countries in the world [16].

This exponential increase in the number of people with diabetes puts an enormous burden on both healthcare authorities and healthcare providers. Prevention and control programs are needed to stem the rising epidemic of diabetes and its complications. However, this will not occur unless governments and public health planners are aware of the potential problem. Surveillance of diabetes is a necessary first step towards its prevention and control, which is now recognized as an urgent priority. Furthermore a reliable baseline status is fundamental to any improvement programs.

To partially fulfill this purpose a cross-sectional, observational study was planned to evaluate the current prevailing scenario of diabetes mellitus management, control, complications, quality of life and psychosocial aspect of patients in order to correlate with the findings of previous studies.

\section{Materials and Methods}

This was non-interventional, cross-sectional, observational study. This study included both type- 1 and type-2 diabetic patients. The study mainly based on primary data. Data was collected from the outpatient department (OPD) of Rajshahi diabetic hospital, a tertiary care diabetic hospital of Rajshahi Diabetic Association. A prospective study was conducted during the month of $\mathrm{Au}-$ gust to September in 2012 in the OPD of Rajshahi diabetic hospital. The present study was involved in a total number of 140 patients of all ages with diabetes visited in the hospital. Patients with diabetes registered in the hospital for more than six months were included in the study. Patients of both male and female are participated in the study. Patients who were unable to answer short list of simple questions were excluded from the study. A standard questionnaire was constructed in local language and interview was administrated in OPD setting. For the selection of sample "Purposive Sampling" technique was used.

The patient was interviewed and data was taken about their diabetes including type of diabetes, level of complication, blood glucose reading, self monitoring data, diabetes education, complications and diabetes management including medication, diet, exercises, and other activities. Patient base line characteristics such as age, sex, risk factors, family history of diabetes, duration of diabetes, medical history, and other health problem related to diabetes, therapeutic management socioeconomic status of the patients was recorded for each patient.

\section{Statistical Methods}

The template is used to format your paper and style the text. All margins, column widths, line spaces, and text fonts are prescribed; please do not alter them. You may note peculiarities. For example, the head margin in this template measures proportionately more than is customary. This measurement and others are deliberate, using specifications that anticipate your paper as one part of the entire proceedings, and not as an independent document. Please do not revise any of the current designations.

\section{Results}

\subsection{Characteristics of the Study Subjects}

A total of 140 patients were included in the study. Sociodemographic characteristics of the study subjects are presented in Table 1.

\subsection{Glycemic Control}

The mean fasting (FBG) and postprandial (PPG) glucose levels of patients measured were $8.9 \pm 3.6 \mathrm{mmol} / \mathrm{l}$ within the range $(4.5-23.0)$ and $11.2 \pm 4.7 \mathrm{mmol} / \mathrm{l}$ within the range (1.6 - 29.0) respectively. Only $25 \%$ patients had FBG level $<6.1 \mathrm{mmol} / \mathrm{L}, 23.9 \%$ had FBG $6.1-7.8$ $\mathrm{mmol} / \mathrm{L}$ and rest $51 \%$ had FBG $>7.8 \mathrm{mmol} / \mathrm{L}$. The mean 
Table 1. Socio-demographic characteristics of the study subjects $(n=140)$.

\begin{tabular}{|c|c|}
\hline Characteristics & Frequency n (percentage \%) \\
\hline Age, years ${ }^{*}$ & $53.2 \pm 10.5$ \\
\hline \multicolumn{2}{|l|}{ Age groups } \\
\hline 25 - 40 years & $16(11.4 \%)$ \\
\hline 41 - 55 years & $71(50.7 \%)$ \\
\hline$>55$ years & $53(37.8 \%)$ \\
\hline Age at onset, years ${ }^{*}$ & $46.9 \pm 9.9$ \\
\hline Duration of diabetes ${ }^{*}$ & $6.3 \pm 5.6$ \\
\hline 1 - 5 years & $85(60.7 \%)$ \\
\hline $6-10$ years & 27 (19.3\%) \\
\hline 11 - 15 years & $22(15.7 \%)$ \\
\hline$>15$ years & $6(4.3 \%)$ \\
\hline \multicolumn{2}{|l|}{ Sex } \\
\hline Male & 60 (42.9\%) \\
\hline Female & 80 (57.1\%) \\
\hline \multicolumn{2}{|l|}{ Education } \\
\hline Illiterate & $24(17.1 \%)$ \\
\hline Primary & $40(28.6 \%)$ \\
\hline Secondary School & $31(22.1 \%)$ \\
\hline Higher Secondary & $28(20 \%)$ \\
\hline Graduate \& Above & 17 (12.1\%) \\
\hline \multicolumn{2}{|l|}{ Occupation } \\
\hline Service Holder & $21(15 \%)$ \\
\hline Businessmen & $24(17.1 \%)$ \\
\hline Housewives & $71(50.7 \%)$ \\
\hline Retirement & $7(5 \%)$ \\
\hline Farmer \& Others & $17(12.2 \%)$ \\
\hline \multicolumn{2}{|l|}{ Marital Status } \\
\hline Single & $2(1.4 \%)$ \\
\hline Married & $111(79.3 \%)$ \\
\hline Widowed & 27 (19.3\%) \\
\hline \multicolumn{2}{|l|}{ Type of diabetes mellitus (DM) } \\
\hline Type-2 DM & 137 (97.9\%) \\
\hline Type-1 DM & $3(2.1 \%)$ \\
\hline \multicolumn{2}{|l|}{ Risk Factors } \\
\hline Family history & $68(48.6 \%)$ \\
\hline Smoking & $15(10.7 \%)$ \\
\hline Both family history \& smoking & $5(3.5 \%)$ \\
\hline
\end{tabular}

*Data expressed as mean \pm SD.
FBG and PPG values increased significantly with the duration of diabetes.

\subsection{Cardiovascular Risk Factors}

Of the 32 patients with dyslipidemia, 19 (59.4\%) were treated with lipid lowering drugs. Statins were the most commonly (36.9\%) prescribed lipid lowering agents. Of the 71 (50.7\%) patients with hypertension, 67 (94.4\%) were taking anti-hypertensive medicine. Beta blockers and $\mathrm{Ca}^{2+}$ antagonist were used by majority of patients (34.7\%) followed by ACE inhibitors (34\%) and angiotensin II receptor blockers (30.9\%).

\subsection{Diabetic Complications}

Data on diabetes-related complications was collected in the study and complications are given in Table 2.

The frequencies of complications were diabetic eye disease (retinopathy) $20(14.3 \%)$, cataract $26(18.6 \%)$, neuropathy symptoms 49 (35\%), nephropathy 9 (6.4\%), angina pectoris $10(7.1 \%)$, cerebral stroke $5(3.5 \%)$, myocardial infarction 8 (5.7\%). Micro-vascular and Macro-vascular complications were reported in 59 (49.2\%) and 15 (10.7\%) patients respectively. Of the 46 patients with retinopathy 15 (32.6\%) patients have eye surgery.

\subsection{Diabetes Management}

Diabetes management data taken from the study subjects are given in Table 3.

Diet, exercise, weight control, and medications are the mainstays of diabetic care. The primary medication used in type-1 diabetes management is insulin, on which the type-1 diabetic patient is dependent for survival. Type-2 diabetic individuals frequently take oral medications

Table 2. Proportion of patients with different complications of diabetes.

\begin{tabular}{|c|c|c|}
\hline Complications of diabetes & $\mathbf{N}$ & $\begin{array}{c}\text { Proportion of } \\
\text { patients (\%) }\end{array}$ \\
\hline Cataract & 26 & 18.6 \\
\hline Diabetic retinopathy & 20 & 14.3 \\
\hline Neuropathy symptoms & 49 & 35.0 \\
\hline Nephropathy & 9 & 6.4 \\
\hline Angina pectoris & 10 & 7.1 \\
\hline Myocardial infarction & 8 & 5.7 \\
\hline Cerebral stroke & 5 & 3.5 \\
\hline Micro-vascular complications ${ }^{*}$ & 59 & 49.2 \\
\hline Macro-vascular complications ${ }^{* *}$ & 15 & 10.7 \\
\hline
\end{tabular}

*Microvascular complications: patients with any or all of following complications-retinopathy, nephropathy and neuropathy; ${ }^{* * *}$ Macrovascular complications: patients with any or all of following complications-angina pectoris, MI, CABG/Angioplasty/Stents, Stroke. 
Tables 3. Diabetes management study.

\begin{tabular}{lc}
\hline Parameters & n (\%) N = 140 \\
\hline Method used to treat diabetes & $14(10 \%)$ \\
No medication & $61(43.6 \%)$ \\
OHA & $35(25 \%)$ \\
Insulin & $30(21.4 \%)$ \\
Both OHA \& insulin & \\
Method used for monitoring glucose level & \\
Glucose level test at the & $109(77.9 \%)$ \\
doctor's office only & $31(22.1 \%)$ \\
Both doctor's office \& home & $26(18.6 \%)$ \\
Have a machine to check blood glucose \\
at home \\
Time spend for physical activity & \\
Did not do exercise & $18(12.9 \%)$ \\
Exercise < 45 min & $46(32.9 \%)$ \\
Exercise > 45 min & $76(54.3 \%)$ \\
Type of doctor patients visit for diabetes & \\
Doctors at diabetic centre's or hospitals & $101(72.2 \%)$ \\
Both GP \& diabetes specialists & $39(27.9 \%)$ \\
Number of visit per year & \\
5 times or more & $87(62.1 \%)$ \\
3 to 4 times & $44(31.4 \%)$ \\
1 to 2 times & $9(6.4 \%)$ \\
Attend diabetes education class & $117(83.5 \%)$ \\
\hline
\end{tabular}

OHA—oral hypoglycemic agent, GP—general practitioner.

although many also use insulin to improve glycemic control.

The majority of the patients receive oral hypoglycemic agent (OHA) 61 (43.6\%) for the management of their diabetes. A number of different oral agents are used by the patients such as biguanides, sulfonylureas, thiazolidinedione, glucosides etc. Some patients take combination of two or more agents. 35 (25\%) patients were treated with insulin and 30 (21.4\%) patients receive both insulin and OHA for their diabetic care. Of them 14 (10\%) patients do not take any medications for their diabetes management. The proportion of patients practicing home blood glucose monitoring was low at 31 (21.1\%); of them 26 (18.6\%) have a machine to check blood glucose at home. Majority of patients 109 (77.9\%) prefer blood glucose monitoring test done at the doctor's office only. About 46 (32.9\%) patients did exercise $<45 \mathrm{~min}, 76$ (54.2\%) patients did exercise $>45 \mathrm{~min}$, while about 18 (12.9\%) respondent did not do any exercise.

Majority of patients 101 (72.1\%) visit the doctors at diabetic centers or hospitals for their diabetes, while few patients 39 (27.9\%) also visit general practitioner. About 87 (62.1\%) patients visit a doctor 5 or more times in a year, 44 (31.4\%) visit 3 to 4 times and 9 (6.4\%) visit 1 to 2 times in a year for his/her diabetes. 88 (62.9\%) patients was performed their blood sugar test one times in the last month, while 37 (26.4\%) two times, 8 (5.7\%) three times and 5 (3.6\%) four times during the last month test their blood sugar. Majority of patients 117 (83.5\%) have received general diabetes education, education on diet and education on foot care.

\subsection{General Health Status of the Patients}

Majority of the patients 65 (46.4\%) answer "good" with the question "would you say your health is", while a few answer "very good" 22 (15.7\%) and a very few answer "excellent" 3 (2.1\%). Some of the patients answer fair 39 (27.9\%) and some patients answer poor 11 (7.9\%). About 15 (10.7\%) patients was hospitalized for uncontrolled blood sugar, 102 (72.9\%) patients feel tired and restless during work or while walking, climbing up stairs, 58 (41.4\%) patients get rashes or allergies on skin and 84 (60\%) patients suffer from depression, stress or sleeplessness. About 16 (11.4\%) patients were taken of work due to illness for diabetes.

\subsection{Patient Perceptions}

When patients were queried about knowledge regarding their blood glucose level, majority of the patients replied that they know their blood glucose level 108 (77.15\%) and 32 (22.9\%) replied don't know their blood glucose level.

When patients were queried about the care and guidance they are having from the diabetic center or clinic or health care provider, majority of the patients answered "quite ok" 106 (75.7\%), few answered "a little bit", while a very few answered "not enough".

Responses to questions on psychological well-being fell largely in the positive territory. At the same time, the majority answered "slightly" [67 (47.9\%)] with the question, "Are your health a worry in your life". Majority answered "not at all" with the questions, "Has your health interfered with your normal social activities with family, friends, neighbors or groups" [66 (47.1\%)], "Has your health interfered with your hobbies or recreational activities" [67 (47.9\%)] and majority answered "slightly" [50 (35.7\%)] with the question, "Has your health interfered with your household chores, errands and shopping”.

\subsection{Physicians' Perceptions}

Majority of physicians preferred to estimate HbA1c. Majority of the physicians preferred to do HbA1c test 4 times a year. Almost all the physicians advocated the self monitoring of blood sugar by patients, and believed that insulin analogues offer distinct advantages over human insulin. All physicians recommended the modern insulin 
delivery devices and believed that patient education helps to achieve treatment goals. All physicians opined that wrong perceptions on insulin use, cost of insulin, fear of injection and other perceptions like insulin usage indicates the end stage of diabetes or insulin means lifelong treatment are the barriers for insulin therapy.

\section{Discussion}

Diabetes Mellitus is a leading cause of death in present world. The risk of dying from diabetes was comparatively reduced than that happened in the past decades in Bangladesh. This was in part the result of increased efforts to improve acute treatment and secondary prevention strategies by the public and private hospitals. In the acute phase, patients require rapid diagnosis and early management to minimize infarct size and to prevent complications. Current guidelines are therefore aimed at optimizing care and outcome of patients with diabetes. The aim of the study was to analyze the clinical course, treatment strategies, management and control in patients with diabetes and to determine to what extent management of diabetes in a tertiary-care diabetic hospital in Bangladesh adhered to current guidelines.

A prospective study was conducted during the month of August to September in 2012 in the outpatient department of a tertiary care diabetic hospital in Bangladesh. The present study was involved in a total number of 140 patients with diabetes mellitus visited in the hospital. In the study, the age was $53.2 \pm 10.5$, age of diabetes onset $46.9 \pm 9.9$, and duration of diabetes was $6.3 \pm$ 5.6 years. In DiabCare Bangladesh, 2008 study, the age of the patients was $50.9 \pm 11.4$, age of diabetes onset$42.1 \pm 14.2$ and duration of diabetes was $7.9 \pm 10.4$ [16]. Our study group comprised of $57.1 \%$ female and $42.9 \%$ male patients with numerous risk factors including family records of diabetes (48.9\%), smoker (10.7\%) and both risk factors (3.5\%) which were similar to that of previous study. Glycemic control appears to be poorer among patients in the present study. The FPG level of patients was $8.9 \pm 3.6 \mathrm{mmol} / \mathrm{L}$ in the present study which was higher than that of DiabCare Bangladesh, 2008 study (8.4 \pm 2.7 $\mathrm{mmol} / \mathrm{L})$. The PPG level appeared to be higher with FPG $(11.2 \pm 4.7 \mathrm{mmol} / \mathrm{L})$.

In the present study, higher proportion of patients had co-morbid hypertension as compared to DiabCare Bangladesh, 2008 study. Studied in various population also identified that hypertension is an independent risk factors for the abnormalities in glucose tolerance [17-21]. So it is important to note that hypertension is the major causes for increasing complications in patients with diabetes. Data on diabetes-related complications was collected in the present study and the frequencies of complications were-cataract (18.6\%), diabetic eye diseases (14.3\%), neuropathy symptoms (35\%), nephropathy (6.4\%), cere- bral stroke (3.5\%), myocardial infarction (5.7\%) and history of angina pectoris was (7.1\%). In Kibriya et al. study the prevalence of diabetic complications werecataract $(13 \%)$, retinopathy $(10.8 \%)$, nephropathy $(8.6 \%)$, neuropathy symptoms (14.4\%), cerebral stoke $(2.2 \%)$ and myocardial infarction (5.2\%). While prevalence of most of the diabetic complications remained similar with previous study, there was high prevalence of neuropathy symptoms, cataract and diabetic eye diseases. Kibriya et al. suggested that, independent of other factors, longer duration of diabetes was associated with all the three microvascular complications: HbAlc with retinopathy \& neuropathy; older age (>60 yr) with nephropathy \& neuropathy; systolic BP > $125 \mathrm{~mm} \mathrm{Hg}$ with nephropathy [22].

Proportion of patients using OHA is decreased to 65\% in the present study from 89.1\% in DiabCare Bangladesh, 2008 study and remains similar with $65.9 \%$ in study of Mahtab et al. [23]. The proportion of patients prescribed with insulin increased two-fold in the present study as compared to DiabCare Bangladesh, 1998 study (46.4\% vs 21.8\%) and similar with DiabCare Bangladesh, 2008 study (42.7\%). Majority of insulin users (47.7\%) experience hypoglycemic reactions.

In the present study, time spent for physical activities is lower. Some people did not do any exercise (12.9\%) to maintain ideal body weight \& controlling blood glucose level. The main reason is that in Bangladesh people are not conscious about their health. Kim et al. found that diabetes is associated with exercise and Veghari et al. identified that physical activity influences diabetes. Also some studies reported that the prevalence of diabetes mellitus in low active people is more than in highly active people [24,25]. So it may conclude that exercise plays an important role for the management of diabetes.

Responses to questions on psychological well-being fell largely in the positive territory. The majority of patients in the present cohort rated their quality of life of to be good or at least acceptable. Majority of physicians preferred to estimate HbA1c test 4 times a year but there is a gap between the frequencies of HbA1c test recommended by the physicians versus real life practice. This gap may be filed by creating awareness on disease progression and related complications. Majority of physicians agreed with the goals of good glycemic control and preventing complications and advocated self monitoring of blood glucose and use of modern insulin devices.

Overall, the fact that majority of patients in the present study cohort had poor glycemic control suggests that there is scope for improvement. The importance of tight glycemic control in preventing chronic complications has been previously underscored by a number of studies [26-30]. Against the background of these studies, there seems to be a need for a large proportion of patients in 
the present study cohort to be upgraded to more intensive pharmacotherapy, with the ultimate goal of preventing the development of late onset complications.

\section{Conclusion}

The present studies carried out in this thesis were performed to evaluate the management, control, complication profile and treatment strategies in patients with diabetes and to determine what extent management of diabetes in a tertiary-care diabetic hospital in Bangladesh adhered to current guidelines.

Patient's poor glycemic control is a concern. Majority of patients (more than 50\%) had FBG and PPG levels above the recommended levels of many guidelines (ADA, EUDPG, APDPG, etc.). To reduce the risk of diabetesassociated complications, glycemia need to be maintained at a satisfactory level. There is a need for a large proportion of patients to be upgraded to more intensive insulin therapy and use of insulin analogues and modern delivery devices can help in achieving these goals effectively. The responses to patient reported outcome tools call for more efforts to improve lifestyle modification, self-testing and awareness and benefits of insulin therapy. As with earlier study, the present study also uncovers gaps in routine diabetes care and will help plan future interventions and monitor outcomes.

As this study was conducted in a single hospital, the result may not be giving the true reflection of the general population. Moreover, the study conducted in a urban hospital where education may be readily accessible, raises further concern as there is more likelihood that the majority of people, especially those living in rural areas and having less access to information, might have even poorer perception and practices.

Therefore, there is a need for increased effort towards developing and making education programs focusing on empowering the persons with diabetes, not only to provide them information but also the ability and empowerment to change knowledge and attitude into practice. Also development and implementation of public health programs should be taken. It is hoped that these findings have major implications for the design of patient education program.

\section{REFERENCES}

[1] R. A. DeFronzo, R. C. Bonadonna and E. Ferrannini, "Pathogenesis of NIDDM: A Balanced Overview,” Diabetes Care, Vol. 15, No. 3, 1992, pp. 318-368. doi:10.2337/diacare.15.3.318

[2] WHO, "Diabetes Action Now: An Initiative of the World Health Organization and the International Diabetic Federation,” WHO, Geneva, IDF, Brussels, 2004, pp. 1-20.

[3] P. Lenzo, "One Adult in Ten will Have Diabetes by
2030,” IDF Diabetes Atlas, Brussels, 2011.

[4] G. Roglic, "Estimates of the Global and Regional Burden of Diabetes,” 4th Edition, IDF Diabetes Atlas, Brussels, 2012.

[5] R. E. Lamb and B. J. Goldstein, "Modulating an Oxidative-Inflammatory Cascade: Potential New Treatment Strategy for Improving Glucose Metabolism, Insulin Resistance, and Vascular Function,” International Journal of Clinical Practice, Vol. 62, No. 7, 2008, pp. 1087-1095. doi:10.1111/j.1742-1241.2008.01789.x

[6] J. S. Johansen, A. K. Harris, D. J. Rychly and A. Ergul, "Oxidative Stress and the Use of Antioxidants in Diabetes: Linking Basic Science to Clinical Practice,” Cardiovascular Diabetology, Vol. 4, No. 1, 2005, p. 5. doi:10.1186/1475-2840-4-5

[7] T. Jaakko, "Reducing Coronary Heart Disease Associated with Type 2 Diabetes: Lifestyle Intervention and Treatment of Dyslipidaemia," Diabetes Research and Clinical Practice, Vol. 61, Supplement 1, 2003, pp. S27-S34. doi:10.1016/S0168-8227(03)00125-6

[8] C. Rafael, “Type 2 Diabetes, Dyslipidemia, and Vascular Risk: Rationale and Evidence for Correcting the Lipid Imbalance," American Heart Journal, Vol. 150, No. 5, 2005, pp. 859-870. doi:10.1016/j.ahj.2005.04.027

[9] M. H. Davidson. "Statin/Fibrate Combination in Patients with Metabolic Syndrome or Diabetes: Evaluating the Risks of Pharmacokinetic Drug Interactions,” Expert Opinion on Drug Safety, Vol. 5, No. 1, 2006, pp. 145-156. doi:10.1517/14740338.5.1.145

[10] M. P. Solano and R. B. Goldberg. "Lipid Management in Type 2 Diabetes,” Clinical Diabetes, Vol. 24, No. 1, 2006, pp. 27-32.

[11] R. Balasubramanian, et al., "Assessment of the Efficacy and Tolerability of a Fixed Dose Combination of Atorvastatin $10 \mathrm{mg}+$ Metformin SR $500 \mathrm{mg}$ in Diabetic Dyslipidaemia in Adult Indian Patients,” Journal of the Indian Medical Association, Vol. 106, No. 7, 2008, pp. 464467.

[12] S. M. Haffner, et al., "Mortality from Coronary Heart Disease in Subjects with Type 2 Diabetes and in NonDiabetic Subjects with and without Prior Myocardial Infarction," The New England Journal of Medicine, Vol. 339, No. 4, 1998, pp. 229-234. doi:10.1056/NEJM199807233390404

[13] H. Miettinem, et al. and the FINMONICA Myocardial Infarction Register Study Group, "Impact of Diabetes on Mortality after the First Myocardial Infarction,” Diabetes Care, Vol. 21, No. 1, 1998, pp. 69-75. doi:10.2337/diacare.21.1.69

[14] J. W. Baynes and S. R. Thorpe, "Role of Oxidative Stress in Diabetic Complications: A New Perspective on an Old Paradigm,” Diabetes, Vol. 48, No. 1, 1999, pp. 1-9. doi:10.2337/diabetes.48.1.1

[15] J. W. Baynes, "Role of Oxidative Stress in Development of Complications in Diabetes,” Diabetes, Vol. 40, No. 4, 1991, pp. 405-412. doi:10.2337/diabetes.40.4.405

[16] Z. A. Latif, A. Jain and M. M. Rahman, "Evaluation of Management, Control, Complications and Psychosocial 
Aspect of Diabetes in Bangladesh: DiabCare Bangladesh 2008,” Bangladesh Medical Research Council Bulletin, Vol. 37, No. 1, 2011, pp. 11-16.

[17] S. Ghosh, A. Collier, M. Hair, I. Malik and T. Elhadd, "Metabolic Syndrome in Type 1 Diabetes," International Journal of Diabetes Mellitus, Vol. 2, No. 1, 2010, pp. 38-42. doi:10.1016/j.ijdm.2009.10.005

[18] K. Kasim, M. Amar, A. A. El Sadek and S. A. Gawad, "Pe-ripheral Neuropathy in Type 2 Diabetic Patients Attending Diabetic Clinics in Al-Azhar University Hospitals, Egypt,” International Journal of Diabetes Mellitus, Vol. 2, No. 1, 2010, pp. 20-23. doi:10.1016/j.ijdm.2009.10.002

[19] S. M. Kim, J. S. Lee, J. Lee, J. K. Na, J. H. Han, D. K. Yoon, S. H. Baik, D. S. Choi and K. M. Chi, "Prevalence of Diabetes and Impaired Fasting in Korea," Diabetes Care, Vol. 29, No. 2, 2006, pp. 226-232. doi:10.2337/diacare.29.02.06.dc05-0481

[20] A. Bener, M. Zirie and A. Al-Rakabi, "Genetics, Obesity and Environmental Risk Factors Associated with Type 2 Diabetes,” Croatian Medical Journal, Vol. 46, No. 2, 2005, pp. 302-307.

[21] A. Gupta, R. Gupta, M. Sarna, S. Rastogi, V. P. Gupta and K. Kothari, "Prevalence of Diabetes, Impaired Fasting Glucose and Insulin Resistance Syndrome in an Indian Population," Diabetes Research and Clinical Practice, Vol. 61, No. , 2003, pp. 69-76. doi:10.1016/S0168-8227(03)00085-8

[22] M. G. Kibriya and H. Mahtab, "Micro-Vascular Complications in Type 2 Diabetes in Bangladesh: The Diabcare-Asia, Bangladesh Project," Diabetes Research Clinical Practice, Vol. 50, Supplement 1, 2000, pp. 135-136.

[23] H. Mahtab and M. G. Kibriya, "The Diabcare-Asia, Bangladesh Project: Management of Diabetes in Bangladesh,” Diabetes Research Clinical Practice, Vol. 50, Sup- plement 1, 2000, p. 55.

[24] W. Patrick, E. H. M. Sullivan, G. Vahram, H. R. Wyatt and J. O. Hill, "Obesity, Inactivity, and the Prevalence of Diabetes and Diabetes Related Cardiovascular Co Morbidities in the US, 2000-2002,” Diabetes Care, Vol. Vol. 28, No. 7, 2005, pp. 1599-1603. doi:10.2337/diacare.28.7.1599

[25] S. G. Wannamethee and A. G. Shaper, "Weight Change and Duration of Overweight and Obesity in the Incidence of Type 2 Diabetes,” Diabetes Care, Vol. 22, No. 8, 1999, pp. 1266-1272. doi:10.2337/diacare.22.8.1266

[26] A. K. Azad, M. A. Kabir, P. K. Roy, A. Raihan, M. T. Rahman and M. Hasan, "Diabetes Mellitus with MultiSystemic Complications,” Bangladesh Journal of Medicine, Vol. 10, 1999, pp. 53-55.

[27] A. B. Anjuman, A. K. Azad, M. A. Alim and E. Saifuddin, "Nutritional Status of Diabetic Patients Attending to a District Level Diabetic Center," The Journal of Teachers Association RMC, Vol. 17, No. 2, 2004, pp. 89-92.

[28] H. Jorgensen, H. Nakayama, H. O. Raaschou and T. S. Olsen, "Stroke in Patients with Diabetes: The Copenhagen Stroke Study,” Vol. 25, No. 10, 1994, pp. 1977-1984. doi:10.1161/01.STR.25.10.1977

[29] D. M. Nathan, J. Lachin, P. A. Cleary and J. Y. Backlund, "Intensive Diabetes Therapy and Carotid Intima-Media Thickness in Type 1 Diabetes Mellitus,” NEJM, Vol. 348, No. 23, 2003, pp. 2294-303. doi:10.1056/NEJMoa022314

[30] H. Sone, S. Mizuno, Y. Ohashi, et al., "Prevention and Therapeutic Strategy of Metabolic Syndrome-Implications from the Interim Results of Japan Diabetes Complications Study (JDCS),” Nippon Rinsho, Vol. 62, No. 6, 2004, pp. 1150-1157. 